\title{
Review Article \\ Industrial Wastes as Auxiliary Additives to Cement/Lime Stabilization of Soils
}

\author{
Jijo James and P. Kasinatha Pandian \\ Tagore Engineering College, Rathinamangalam, Melakottaiyur, Chennai 600127, India \\ Correspondence should be addressed to Jijo James; jijothegreat@gmail.com
}

Received 13 November 2015; Accepted 10 January 2016

Academic Editor: Hossein Moayedi

Copyright (C) 2016 J. James and P. K. Pandian. This is an open access article distributed under the Creative Commons Attribution License, which permits unrestricted use, distribution, and reproduction in any medium, provided the original work is properly cited.

\begin{abstract}
Chemical stabilization involves the use of chemical agents for initiating reactions within the soil for modification of its geotechnical properties. Cement and lime stabilization have been the most common stabilization methods adopted for soil treatment. Cement stabilization results in good compressive strengths and is preferred for cohesionless to moderately cohesive soil but loses effectiveness when the soil is highly plastic. Lime stabilization is the most preferred method for plastic clays; however, it proves to be ineffective in sulphate rich clays and performs poorly under extreme conditions. With such drawbacks, lots of researches have been undertaken to address the issues faced with each stabilization method, in particular, the use of solid wastes for soil stabilization. Solid waste reuse has gained high momentum for achieving sustainable waste management in recent times. Research has shown that the use of solid wastes as additives with and replacement for conventional stabilizers has resulted in better results than the performance of either individually. This review provides insight into some of the works done by earlier researchers on lime/cement stabilization with industrial wastes as additives and helps to form a sound platform for further research on industrial wastes as additives to conventional stabilizers.
\end{abstract}

\section{Introduction}

Industrial revolution was a major milestone in the history of human civilization. Since the dawn of machines and industrialization of various manufacturing processes, there has been a rapid boom in development and urbanization surrounding industrial centers. The standard of living of the society started to rise but the standard of the living environment started to decline. It was not noticed until it started affecting humans directly. Today, industrial waste management is an area of concern with tons of waste being generated each day. To cite an example, according to central electricity authority of India, the fly ash (FA) production in the year 2014-2015 was 184.14 million tons [1]. But, with mounting waste management problems, there have been a lot of efforts to convert this area of concern into an area of opportunity by reutilizing the industrial wastes for various purposes. Citing the same example, the utilization of FA in various avenues due to conscious efforts by various agencies including the government of India resulted in reuse of 102.54 million tons of
FA in the year 2014-2015 [1]. Though the utilization of 102.54 million tons of FA in 2014-2015 is only $55.69 \%$ of the total generation, it is higher than the utilization of 100.37 million tons of FA (against a generation of 163.56 million tons) in the year 2012-2013 [2]. The various modes of utilization of FA shown in Figure 1 reveal that FA utilization in roads and flyover and reclamation of low lying areas account for about $14 \%$ in total reutilization.

The reutilization of FA in the area of soil modification including reclamation, roads, and embankment works is depicted in Figure 2 and it can be understood that the utilization of the waste has steadily increased over the years, especially in the construction of roads and embankments. Thus, it can be observed that reutilization of solid wastes in the modification of soil characteristics is a potential avenue for sustainable management of solid wastes generated. The example cited deals only with FA, whereas there are several other industrial solid wastes being generated in India. The major solid wastes generated in India are tabulated in Table 1. From Table 1, it can be concluded that FA is one of the single 


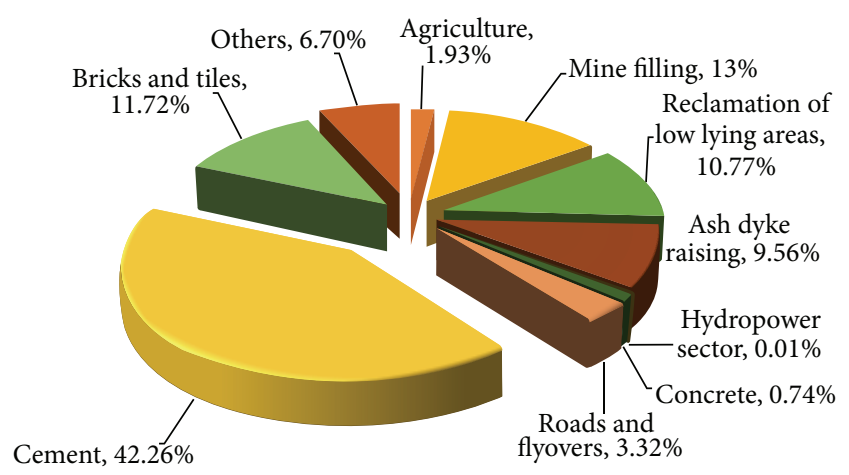

FIgURE 1: Modes of utilization of FA in the year 2014-15 [1].

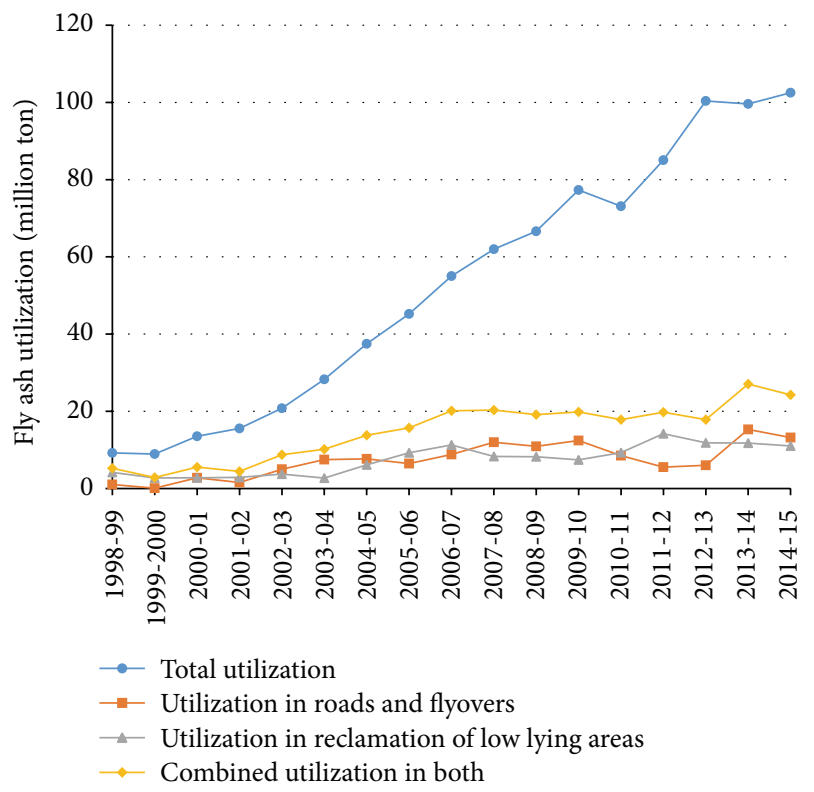

FIGURE 2: Utilization of FA in areas of soil engineering [1-5].

largest industrial solid wastes produced in India followed by steel slag, phosphogypsum (PG), and blast furnace slag. The figure for mine rejects is the combined waste produced from various sources and types of mines.

Thus, industrial wastes reuse in soil stabilization is a relatively new avenue for effective utilization and management of solid wastes. Along with soil stabilization, use of industrial solid wastes in geotechnical fill applications can be an effective avenue for waste management purposes. However, utilization of solid wastes in geotechnical fill applications is a different aspect of soil engineering which is not going to be dealt with in this paper. A few earlier authors have reviewed the use of solid wastes in soil improvement [6-8]. However, these treat application of solid wastes as a whole in all combinations and have not differentiated between solid wastes as a standalone stabilizer and as auxiliary additives to primary stabilizers. In this paper, only the utilization of solid wastes as auxiliary additives has been dealt with. The reason for this approach is the difference in stabilization
TABLE 1: Major industrial solid wastes generated in India.

\begin{tabular}{lcc}
\hline Name of the solid waste & Annual production (million tons) \\
\hline FA & 184.14 & {$[1]$} \\
Blast furnace slags & 10 & {$[9]$} \\
Steel slag & 12 & {$[10]$} \\
Red mud & 4.71 & {$[11]$} \\
Lime sludge & 4.5 & {$[12]$} \\
Lead-zinc slag & 0.5 & {$[12]$} \\
Phosphorus furnace slag & 0.5 & {$[12]$} \\
PG & 11 & {$[13]$} \\
Jarosite & 0.6 & {$[12]$} \\
Kimberlite & 0.6 & {$[12]$} \\
Mine rejects & 750 & {$[12]$} \\
\hline
\end{tabular}

performance achieved by solid wastes as stabilizers and solid wastes as additives to primary stabilizers.

\section{Industrial Wastes as Additives to Lime/Cement in Soil Stabilization}

Chemical stabilization is a major category of soil stabilization involving the use of chemical agents for initiating reactions within the soil for modification of its geotechnical properties. Cement and lime stabilization have been the most common stabilization methods adopted for soil treatment. Cement stabilization results in good compressive strength and is preferred for cohesionless to moderately cohesive soil but loses effectiveness in the case of highly plastic soil. Lime stabilization is the preferred method of treatment for plastic clays; however, it is ineffective in sulphate-rich clays and performs poorly under extreme conditions. In the light of such drawbacks, a lot of research has been undertaken to address the issues faced with each stabilization method, particularly the use of solid wastes. Reuse of solid wastes has gained a lot of priority for achieving sustainable waste management and, hence, they have been adopted in soil stabilization as standalone stabilizers as well as additives to augment the performance of conventional stabilizers like lime and cement. Sabat and Pati [6] classified solid wastes into four major categories based on their source of generation as (i) industrial, (ii) agricultural, (iii) domestic, and (iv) mineral solid wastes. In the present review, however, the authors have not tried to classify based on source but have tried to discuss most frequently adopted and researched solid waste materials in soil stabilization.

2.1. Lime/Cement Stabilization Reactions. Before going into the effect of additives on lime and cement stabilization, an understanding of the chemical reactions resulting upon addition of additives to the soil is inevitable. The addition of lime to soil initiates several reactions. Lime soil reactions can be broadly classified into short term and long term reactions. The short term reactions include ion exchange, flocculation [14], and carbonation [15]. The long term pozzolanic 
reactions include formation of reaction products which affects the strength and compressibility of clays [16].

Lime treatment of soil results in immediate ion exchange in which divalent calcium ions ionized from lime (1) normally replace univalent cations $\left(\mathrm{M}^{+}\right)$on the clay surface (2) and ions in high concentration will replace those in a lower concentration [17]:

$$
\begin{aligned}
& \mathrm{Ca}(\mathrm{OH})_{2} \longrightarrow \mathrm{Ca}^{2+}+2(\mathrm{OH})^{-} \\
& \mathrm{Ca}^{2+}+\text { Clay Mineral- } \mathrm{M}^{+} \\
& \longrightarrow \text { Clay Mineral- } \mathrm{Ca}^{2+}+\mathrm{M}^{+}
\end{aligned}
$$

The short term reactions improve soil plasticity, making it easier to work with, and improve uncured strength and loaddeformation properties.

Long term pozzolanic reactions involve reactions between lime, water, soil silica, and soil alumina. High alkaline soil $\mathrm{pH}$ during lime treatment stimulates dissolution of siliceous and aluminous compounds from the clay mineral structure. These dissolved compounds react with calcium ions in pore water to form calcium silicate hydrate (CSH) and calcium aluminate hydrate $(\mathrm{CAH})$ gels, which cover the soil particles and later crystallize to link them [18]. The basic form of the pozzolanic equations is given as follows $[17,19,20]$ :

$$
\begin{aligned}
& \mathrm{Ca}^{2+}+\mathrm{OH}^{-}+\mathrm{SiO}_{2}(\text { soluble clay silica }) \longrightarrow \mathrm{CSH} \\
& \mathrm{Ca}^{2+}+\mathrm{OH}^{-}+\mathrm{Al}_{2} \mathrm{O}_{3}(\text { soluble clay alumina }) \\
& \longrightarrow \mathrm{CAH}
\end{aligned}
$$

The long term pozzolanic reactions are time dependent and curing is essential for developing strength and durability.

Portland cement is composed of calcium silicates and calcium aluminates that, when combined with water, hydrate to form the cementing compounds of $\mathrm{CSH}$ and $\mathrm{CAH}$, as well as excess calcium hydroxide. Pozzolanic reaction between calcium hydroxide released during hydration and silica and alumina of soil occurs in fine-grained clay soils and is an important aspect of stabilization of these soils [21]. Thus, it can be noted that cement-soil reactions are similar to that of pozzolanic reactions of lime with soil.

2.2. FA. FA is a waste that is obtained as a result of power generation from coal/lignite based thermal power plants. For a country like India, such thermal power plants form the backbone of capacity addition $[1,2,4]$. Indian coal is of low grade and has an ash content of $30-45 \%$. Thus, huge quantities of FA are produced resulting in pollution of air and water. The utilization of FA in soil modification can prove to be a useful avenue to augment the areas of FA waste management.

Ji-ru and Xing [22] studied the effects of stabilizing expansive soils with lime and FA. Expansive soils are the soils which swell significantly when they come in contact with water and shrink when the water squeezes out [2325]. Lime and FA were added to an expansive soil in the range of $4-6 \%$ and $40-60 \%$ by dry weight of soil, respectively.
The stabilized soil specimens were then tested for their chemical composition, grain size distribution, consistency limits, compaction, California Bearing Ratio (CBR), free swell, and swell capacity. The authors concluded that the addition of lime resulted in increase in plastic limit, whereas addition of FA resulted in decrease in liquid limit, thereby reducing the plasticity index of the expansive soil sample. The CBR values of FA-lime stabilized soil were higher than both only lime stabilized and only FA stabilized soils. The combination also resulted in the least plasticity index of the soil. It was concluded that $4-6 \%$ of lime and $40-50 \%$ of FA were optimal for stabilization of the expansive soil.

Sharma et al. [26] carried out a micro level investigation of stabilization of clayey soil with lime and FA. The optimum dosage of FA was found out by conducting unconfined compression (UCC) strength tests, CBR, free swell index, and Atterberg limits. The minimum lime content was found out using the Eades and Grim $\mathrm{pH}$ test. Micro level investigation was performed by scanning electron microscopy (SEM), Xray diffraction (XRD) analysis, thermogravimetric analysis (TGA), energy dispersive spectroscopy (EDS), and zeta potential. The optimum FA content was identified as $20 \%$ and minimum lime content was found as $8.5 \%$. It was found that $20 \%$ FA was not enough for improving the strength of the soil to be used as a good foundation material; hence, the soil was stabilized with the combination of $20 \%$ FA and $8.5 \%$ lime which produced better strength. XRD and SEM analysis confirmed the formation of new reaction products, calcium silicate hydrate, and calcium aluminate hydrate in the stabilized soil due to the progression of pozzolanic reactions.

Mishra [27] attempted to improve the strength of clayey soil by means of adopting locally available FA as additive to lime in soil stabilization. The soil was stabilized using FA in increments of $10 \%$ up to a maximum of $30 \%$ with $2 \%$ and $3 \%$ lime combinations. It was found that the CBR of soil-FA-lime combinations of $70: 30: 3$ was as high as $55 \%$ against the CBR of virgin soil at $2.3 \%$. The author recommended the use of this combination for stabilization of subgrades as it involved the maximum utilization of FA while producing significantly high CBR value.

Mccarthy et al. [28] studied the engineering and durability properties of FA treated lime stabilized sulphate bearing soils. Two clay soils were stabilized with lime, two types of FA, and Ground Granulated Blast furnace Slag (GGBS) for studying the control of swell associated with lime stabilization of sulphate bearing soils. The stabilized soil consisted of quick lime up to $3 \%$, FA up to $24 \%$, and GGBS up to $9 \%$ by weight. The stabilized soils were tested for immediate bearing index, UCC strength, indirect tensile strength, frost heave, and water permeability. The study concluded that addition of FA and GGBS to lime stabilized clayey soils increased its immediate bearing index, UCC strength, and indirect tensile strength and GGBS to lime stabilized soils improved the performance of the stabilized soils based on the optimal dosage of the industrial wastes.

Kolay et al. [29] investigated the effect of addition of quick lime, cement, and FA on the stabilization of peat soil from Sarawak region of Indonesia. Soil samples were collected from six different locations of Sarawak and were 
stabilized using the aforementioned stabilizers in the range of 5-20\%, except for FA which was adopted in the range of $2-8 \%$. The authors also studied the combination of FA and quicklime to investigate the combined effect of the stabilizers. SEM was used to perform a microstructural analysis to understand the changes in stabilized soil structure. The samples were cured for periods of 7,14 , and 28 days. The study concluded that the combination of quick lime and FA produced higher strengths of stabilized peat soil when compared to stabilization with either quick lime or FA as standalone stabilizer. It was observed that cement produced the best results in stabilization of peat soil but $80 \%$ of the strength produced by $20 \%$ Portland cement was achieved by a combination of $15 \% \mathrm{FA}$ and $6 \%$ quick lime, thereby indicating the effectiveness of combining industrial wastes with conventional stabilizers. Microstructural analysis using SEM clearly indicated structural changes in the stabilized soil samples. The stabilized soil samples exhibited a denser soil structure.

Shah et al. [30] examined the adverse effects of fuel oil contamination on the geotechnical properties of soil and its stabilization with lime, cement, and FA and also their combinations. Contaminated soil samples were collected from 16 different locations in a petrochemical industrial area in Vadodara district of Gujarat, India. The contamination levels of fuel oil were found to be in the range of 7 to $10 \%$. Additional contaminated soils were developed in the laboratory by adding $10 \%$ fuel oil to uncontaminated soil and mixing it thoroughly using a mixer and curing it in a closed container at ambient temperature for a period of 7 days. The naturally contaminated soils as well as the artificially generated contaminated soils were tested for their Atterberg limits and compaction characteristics and classified. The contaminated soils were then stabilized with lime, cement, and FA in proportions of 5,10 , and $20 \%$ as well as combinations of the three with the maximum binder content not exceeding $20 \%$. It was observed that addition of lime produced the best stabilization among individual stabilizers with a strength gain of $315 \%$ over virgin soil. However, the blends of $10 \%$ lime and $10 \% \mathrm{FA}$ and $10 \%$ lime, 5\% FA, and 5\% cement produced strength gains of $328 \%$ and $371 \%$, respectively. The latter combination also produced the best reduction in plasticity index of the contaminated soils. It was concluded that the combinations of lime, FA, and cement result in the dispersion of fuel oil, cation exchange, and pozzolanic reactions between the three results in strength gain.

Wang et al. [31] explored the strength and deformation behavior of Dunkirk marine sediments with cement, lime, and FA. The study mainly emphasized on the deformation characteristics of marine sediments. A series of UCC strength tests were performed after curing periods of $14,28,60$, and 90 days to study the effect of binder content. The binders were mixed with wet soil and mechanically mixed with an agitator for a minimum period of 3 minutes. The blended soil samples were cast into cylindrical specimens, moulded at their optimum moisture content (OMC) and maximum dry density (MDD) for various combinations of binders by static compaction. The dimensions of the samples were $50 \mathrm{~mm}$ $\times 100 \mathrm{~mm}$, which were demoulded. The samples were then immediately stored in sealed plastic containers for curing to avoid moisture changes. The microstructural changes were analyzed using SEM. It was noticed that addition of binders resulted in increase in strength of the stabilized sediments. The addition of FA to lime stabilization further enhanced its strength; however, for the present soil sediment, addition of FA to cement stabilization resulted in a drop in the strength of the sediment. The microstructure analysis was used to explain the behavior in lime and cement stabilization of sediments admixed with FA. In the case of lime stabilization with FA, the destruction of the structure of FA was observed in SEM resulting in its effective participation in the pozzolanic reactions, whereas, in cement stabilization, no evidence of the destruction of FA structure could be witnessed. Thus, it was concluded that only small amount of FA participates in the stabilization reaction resulting in strength reduction.

Bhuvaneshwari et al. [32] investigated the capability of lime and combinations of lime and FA in improving the properties of a dispersive clay. Soils that are dislodged easily and rapidly in flowing water of low salt concentration are called dispersive soils. The experimental investigations involved free swell tests, double hydrometer tests, pinhole tests, crumb tests, and chemical tests. A microstructural analysis was also carried out using SEM for investigating changes taking place at the micro level. It was seen that the addition of $5 \%$ lime and combination of $2 \%$ lime and $15 \%$ FA was capable of reducing the free swell from $1000 \%$ for virgin soil to $400 \%$. Addition of $5 \%$ lime and $2 \%$ lime with $15 \%$ FA reduced the dispersion from $71 \%$ to $9.5 \%$ and $1 \%$, respectively. Addition of lime and FA resulted in the change in classification of the dispersive clay. Microstructural investigation clearly revealed a change in the fabric of the clay.

2.3. Rice Husk Ash (RHA). RHA is generated due to the burning/incineration of rice husk generated in paddy farms as a waste material. RHA contains very high amounts of silica and can be used as a pozzolan in lime and cement mixtures [33]. Thus, utilization of RHA in combination with lime and cement is a foregone conclusion. This section describes some works related to utilization of RHA in soil stabilization.

Bagheri et al. [33] studied the strength and mechanical behavior of soil stabilized with cement, lime, and RHA. Consolidated undrained triaxial and UCC tests were performed to estimate the potential of mixtures of cement-lime and cement-lime-RHA. The study investigates the influence of the combined amount of stabilizer, main effective stress, and curing days on soil strength, deformation, postpeak behavior, and brittleness. The combined stabilizer dosage was varied from 2.5 to $12.5 \%$ by dry weight of soil and cured for periods of $3,7,28$, and 60 days. It was noticed that the addition of the stabilizer combination resulted in an increase in the peak strength and postpeak strength of the stabilized soil. The results showed that RHA increased the strength of the stabilized soil significantly and reduced the environmental impact of cement and lime additives.

Basha et al. [34] explored the utilization of RHA along with cement for stabilization of a residual soil. The experimental programme involved the determination of consistency limits, compaction characteristics, UCC strength, and 
CBR values. Microstructural changes were studied using SEM and XRD analysis. The results of the investigation revealed that the UCC strength of cement stabilized soil increased with addition of RHA. There was also an increased resistance to immersion of the stabilized soil with RHA addition. The CBR value of the stabilized soil multiplied with the addition of RHA. It was concluded that a combination of $6-8 \%$ cement and $15-20 \%$ RHA was sufficient for optimal improvement in soil properties.

James et al. [35] investigated the effect of addition of lime on the index properties of RHA stabilized soil. Soil stabilized with 3 different RHA contents was admixed with increasing lime content and Atterberg limits and free swell of the soil were tested. It was found that the addition of lime to RHA resulted in improvement of soil properties when compared to pure RHA stabilization. It was concluded that $12 \%$ RHA with $6 \%$ lime gave the best results in improving the index properties of the soil.

Jha and Gill [36] delved into the effect of RHA on lime stabilization of soil. The soil sample was crushed using mallet and sieved through IS $2.36 \mathrm{~mm}$ sieve and dried in the oven at a temperature of $105^{\circ} \mathrm{C}$. RHA was also prepared in a similar manner. The soil, RHA, and lime slurry, in the required quantities, were mixed together in a mechanical mixer thoroughly. The test specimens were all prepared as per Indian Standards for various tests. The stabilized soil samples were tested for their compaction characteristics, strength, CBR, and durability characteristics. The test results concluded that the addition of RHA to lime stabilization enhanced the development of UCC strength of the soil. The strength development depended on the curing period and temperature of curing. Addition of RHA also enhanced the durability of lime stabilized soil in addition to increased soaked as well as unsoaked CBR of the soil.

Choobbasti et al. [37] investigated the effect of addition of RHA to lime stabilization of soil. An extensive experimental programme was conducted to determine various properties of lime stabilized soil including Atterberg limits, compaction characteristics, CBR, and direct shear strength. They concluded that addition of RHA to lime stabilization of soil resulted in a reduction in plasticity of the soil and increase in the shear strength and CBR of the soil.

Muntohar et al. [38] researched the stabilization of silty clay with lime and RHA reinforced with waste plastic fibres. The soil was mixed with lime and RHA along with $50 \%$ of OMC to obtain a uniformly mixed hydrated soil sample in the first stage. In the second stage, waste plastic fibres were added and mixed carefully so that the fibres did not get lumped up in order to ensure uniform distribution of fibres throughout the stabilized soil. UCC strength specimens were prepared in a constant volume mould of $50 \mathrm{~mm} \times 100 \mathrm{~mm}$ whereas triaxial test specimens were prepared in a mould of $76 \mathrm{~mm}$ $\times 38 \mathrm{~mm}$ at their OMC and MDD. CBR and durability tests were also performed on the stabilized soil specimens. The results of the investigation revealed that addition of lime and RHA to soil increased its compressive and tensile strength by 4 and 5 times, respectively. The CBR value of the soil increased 3.6 times due to addition of lime and RHA. The addition of plastic fibres to this mixture further improved the strength and durability of the stabilized soil samples, with CBR values increasing by 8.7 times.

Sharma et al. [39] explored the behavior of remoulded clays blended with lime, calcium chloride, and RHA. The effect of addition of RHA on lime and calcium chloride stabilization of clayey soil was studied through UCC and CBR tests. The samples were prepared at a water content of $24 \%$ after thoroughly mixing the soil with the requisite quantities of lime and RHA/calcium chloride and RHA combinations and curing the blend for a period of 28 days in an incubator. After curing, the stabilized samples were compacted in a Harvard mould of dimensions of $40 \mathrm{~mm} \times 80 \mathrm{~mm}$ in four layers of $20 \mathrm{~mm}$ each. It was found that the addition of RHA to lime stabilized soil increased the UCC strength of the stabilized soil by $127 \%$ and the CBR increased by $191 \%$ when $12 \%$ RHA was added to $4 \%$ lime stabilization, which was found to be the optimal blend. In the case of calcium chloride stabilization, an addition of $12 \%$ RHA to $1 \%$ calcium chloride stabilized soil resulted in an increase in the UCC strength by $56 \%$ and CBR by $23 \%$.

Roy [40] tested the effect of combining RHA and cement in stabilization of clay of high plasticity. The investigation involved studying the effect of RHA on 6\% cement stabilized soil. The MDD, OMC, CBR, and UCC strength of the stabilized soil were determined. The results of the investigation revealed an increase in MDD and reduction in OMC with increase in RHA content. The results of the UCC test and CBR test revealed that 10\% RHA was optimal to increase the strength and CBR of the soil.

Olgun [41] investigated the performance of soil stabilized with lime and RHA reinforced with fibres subject to freezethaw conditions. The lime content was varied between $2 \%$ and $8 \%$, RHA content between 0 and $15 \%$, and fibre content between 0 and $0.8 \%$. The samples were cured for a period of 28 days and subjected to 7 freeze-thaw cycles. At the end of the curing period, the samples were subject to UCC strength tests and swelling tests. It was inferred that lime was the most influential parameter in determining the strength of non-freeze-thaw subjected samples whereas RHA was the most influential parameter in the case of samples subjected to freeze-thaw. Lime and fibre content both were effective on the axial strain. In the case of swelling test, lime was effective for non-freeze-thaw samples whereas RHA was effective in the case of samples subjected to freeze-thaw. From the study, it was concluded that, for samples subjected to freeze-thaw, the optimal lime content reduced whereas the optimal RHA content increased.

2.4. Blast Furnace Slag. Blast furnace slag is nonmetallic byproduct of iron ore smelting. It is formed when iron ore, coke, and flux are melted together in a blast furnace. At the completion of the metallurgical smelting process, the lime in the flux chemically combines with the silicates and aluminates in the ore and coke ash to form slag. During the period of cooling and hardening, depending on the cooling method, blast furnace slag can form several products including granulated slag, air-cooled slag, expanded slag, aircooled blast furnace slag, air-cooled blast furnace slag rip rap, and slag cement [42]. 
Wild et al. [43] tried to extend the beneficial applications of GGBS, namely, enhanced durability, chloride penetration resistance, sulphate attack resistance, and protection against alkali silica reaction to pavement, and other foundation soil applications by partial replacement of lime in soil stabilization with GGBS. Samples were prepared at mean MDD and OMC by thoroughly mixing soil, lime, and GGBS in a mixer and compacting them in constant volume mould of dimensions of $50 \mathrm{~mm} \times 100 \mathrm{~mm}$ and cured in plastic bags placed in chambers maintained at $30^{\circ} \mathrm{C}$ and $100 \%$ relative humidity. The samples were cured for periods of 7 days and 28 days and were tested for their UCC strength. A few selected samples were used for mineralogical study through XRD analysis. It was deduced that partial substitution of lime with GGBS resulted in enhanced strength at 7 days as well as 28 days of curing. The development of strength was observed in both high lime low slag with gypsum and low lime high slag without gypsum trials. In the former, gypsum played a role in acceleration of strength development due to formation of crystalline ettringite, whereas, in the latter, the strength development was due to lime activated hydration of slag.

Celik and Nalbantoglu [44] studied the effect of GGBS on the control of swell associated with lime stabilized sulphate bearing soils. In order to study the effect of swelling associated with lime stabilization of sulphate-rich soils, three different concentrations of sulphate were chosen, namely, 2000, 5000, and 10,000 ppm. The compaction characteristics, Atterberg limits, linear shrinkage, and swell potential of sulphate dosed $5 \%$ lime stabilized soil were then investigated. The same tests were repeated on the combinations but with $6 \%$ GGBS as an additive. The test results revealed that the presence of sulphate in soil resulted in abnormal plasticity and swell potential of the soil. At 10,000 ppm sulphate concentration, the swell potential of the lime stabilized soil was three times higher than the natural soil. However, on addition of $6 \%$ GGBS, the swell potential of lime stabilized soil drops to $1 \%$ from $8 \%$ for $10,000 \mathrm{ppm}$ sulphate concentration. In contrast, there was no swelling at all for 5000 ppm sulphate concentration. Hence, this suggested that addition of GGBS to lime results in effective control of swell associated with ettringite formation in sulphate bearing soils.

Obuzor et al. [45] evaluated the performance of lime activated GGBS in stabilizing road pavements and embankments constructed in flood plains that are prone to submerged conditions due to flooding. Laboratory simulated flooding conditions were used to gauge the performance of stabilized soil specimens of size of $50 \mathrm{~mm} \times 100 \mathrm{~mm}$. The samples were immersed in water for periods of 4 and 10 days after periods of $7,14,28,56$, and 90 days of curing. The specimens were subjected to durability index and UCC strength tests. The samples were prepared with a maximum stabilizer dosage of $16 \%$ and five different combinations of lime and GGBS were adopted with GGBS replacing lime in increments of $4 \%$ in each successive combination. The samples were moulded at three different moisture contents at their MDD to study the effect of placement water content. The investigation revealed that $4 \%$ lime with $12 \%$ GGBS produced the highest strength and durability out of all the combinations. The strength of the stabilized soil increased with decrease in lime content and increase in GGBS content in the mix, thereby giving a clear indication of better performance of lime-industrial waste combinations when compared to pure lime or pure industrial waste stabilization. It is evident that strength of lime-clay systems was hugely dependent on the GGBS component which increases the density and permeability of the system by forming cementitious gels.

Obuzor et al. [46] investigated the durability of flooded low capacity soil by treating it with lime and GGBS. The investigation involved preparation of test specimens of $50 \mathrm{~mm}$ diameter and $100 \mathrm{~mm}$ height, statically compacted to their MDD and OMC, followed by moist curing and simulated flooding of the samples. Water absorption during flooding was measured followed by testing of UCC strength of the samples. It was found that higher lime content resulted in greater water absorption. The addition of GGBS, however, resulted in a reduction in moisture absorption and increase in the strength of the flooded samples. It was determined that the addition of GGBS resulted in the reduction in resource consumption and improved robustness of the roads.

Kogbara and Al-Tabbaa [47] investigated the potential of cement and lime activated GGBS in solidification/containment of leaching of heavy chemicals. The investigation involved preparation of an artificial heavy metals spiked soil and treating it with combinations of 1:4 lime to GGBS and 1:9 cement to GGBS. Three binder dosages of 5,10 , and $15 \%$ were adopted and stabilized samples were compacted to their maximum dry densities. The assessment of the stabilization process was done by conducting UCC strength, permeability, and acid neutralization capacity tests. Leachability test for determining contaminants at different acid concentrations was also performed. The study suggested that the combinations of cement-GGBS and lime-GGBS were capable of not only increasing the strength of the stabilized soil but also reducing the permeability and leachability to within prescribed standards. It was seen that cementGGBS performed better than lime-GGBS combination in controlling leaching of contaminants.

Vijayaraghavan et al. [48] investigated the performance of alternate bricks made of cement stabilized mud with slag as additive. The investigation consisted of determination of compressive strength, water absorption, and efflorescence. It was found that addition of optimal dosage of cement to mud in manufacture of bricks produced higher strength when compared to conventional burnt brick. The water absorption of optimal cement stabilized brick was also lesser than that of burnt clay brick. However, it was observed that addition of slag to the composition of cement stabilized brick produced even better compressive strength and lesser water absorption. All combinations of cement as well as cement-slag stabilized mud bricks showed no signs of efflorescence. Thus, at end of the study, the authors recommended the use of alternate bricks as a cost-effective material for low cost housing.

2.5. $P G$. PG is a waste by-product from the processing of phosphate rock by the wet acid method of fertilizer production that currently accounts for over $90 \%$ of phosphoric acid production $[49,50]$. The worldwide production of PG is estimated to be in the range of 100-280 million tons per 
year $[50,51]$, based on the general rule that $4.5-5$ tons of PG is generated for every ton of phosphoric acid produced $[13,50,52]$. However, the utilization of PG in construction materials is low because of the presence of naturally occurring radioactive materials including $\mathrm{Ra}-226$ [49, 50, 53, 54]. Shweikani et al. [55] found that radiation dose due to addition of PG in cement was within the prescribed international standards for construction materials.

Degirmenci et al. [49] studied the use of PG with FA and PG with cement in stabilization of two different types of soil. The investigation involved the determination of effect of PG with cement and PG with FA on the plasticity, compaction characteristics and strength of the stabilized soil. The results of the investigation showed that addition of PG and cement to soil resulted in a reduction in the plasticity of the stabilized soil. The addition of PG and cement to one soil type resulted in an increase in the MDD and reduction in the OMC whereas a reverse trend was seen for the other soil type. The stabilization of the soils with cement and PG resulted in an increase in UCC strength of the soils. The strength of soils stabilized with PG and cement was higher than the strength achieved by stabilization with PG and FA.

Kumar et al. [56] studied the stabilization of bentonite clay with a combination of lime and PG. The content of lime and PG was varied from 0 to $10 \%$. The stabilized soil was tested for its consistency limits, compaction characteristics, free swell index, percent swell, UCC strength, and CBR value. The tests were performed in accordance with relevant Indian Standard codes. The authors found that $8 \%$ lime was the optimal lime content for stabilization of bentonite. On addition of PG to lime stabilized soil, the strength of the soil increased with increase in PG content up to $8 \%$ beyond which there was a reduction in strength of the soil. The addition of $8 \%$ PG also increased the CBR, modulus of subgrade reaction, and the secant modulus of the stabilized soil. The addition of PG also resulted in reduced swelling. It was concluded that the addition of PG to lime would be a boost to pavement construction on such poor soils.

Ghosh [57] investigated the stabilization of pond ash using combination of lime and PG. The investigation aimed at improving the geotechnical properties of class $\mathrm{F}$ pond ash for construction of road base and subbase construction by using lime and PG in proportions of 4,6 , and $10 \%$ and 0.5 and $1 \%$, respectively. The compaction characteristics of pond ash were determined using standard and modified proctor compaction tests. The stabilized soil samples were used to prepare bearing test samples in moulds of $152 \mathrm{~mm}$ diameter and $178 \mathrm{~mm}$ height at their OMC and maximum dry densities for different combinations. The samples were covered with clean wrap and cured for periods of 7,28, and 45 days in a humidity chamber. The results of the bearing test revealed that addition of small quantities of PG to lime stabilized pond ash resulted in increase in bearing ratios across all combinations tested. It was also observed that addition of PG to lime produced higher bearing for soaked samples than for unsoaked samples. The effect of PG addition was more prominent at lower lime content than higher lime contents. It was opined that lime stabilized pond ash admixed with PG may find potential applications in road construction.
James and Pandian [58] had investigated the effect of PG on the strength of lime stabilized soil. Three different lime contents, namely, initial consumption of lime (ICL), optimum lime content (OLC), and one trial dose below ICL, were adopted for stabilization of an expansive soil. The strength of lime stabilized soil was determined by preparing UCC tests samples in a split mould of diameter $38 \mathrm{~mm}$ and height $76 \mathrm{~mm}$ and cured for periods of 2 hours and 3, 7, 14, and 28 days. The results of the investigation revealed that the addition of PG to lime resulted in an increase in the early as well as delayed strength of lime stabilized soil. It was also found that optimal PG dosage for achieving strength gain increased with increase in lime content, which was indicative of better utilization of PG in the pozzolanic reactions when sufficient lime was available.

Kumar and Dutta [59] investigated the potential of sisal fibres in enhancing the UCC strength of PG admixed lime stabilized bentonite. The sisal fibre content was varied from $0.5 \%$ to $2 \%$. The addition of PG resulted in an increase in the dry density and OMC of the lime-bentonite mix whereas an opposite trend was noticed on addition of sisal fibres. The results indicated that the addition of PG and sisal fibres to lime stabilized bentonite resulted in an increase in the strength. It was also observed that $8 \%$ lime with $8 \%$ PG and $1 \%$ sisal fibres produced the highest UCC strength. The addition of sisal fibres also enhanced the residual strength of the mix. The authors concluded that the addition of PG and sisal fibres will enhance the performance of temporary roads constructed on problematic soils.

2.6. Bagasse Ash (BA). India is one of the largest growers of sugarcane with an annual production of 342.56 million tons in the year 2011-12 [60]. The sugar manufacturing process generates solid wastes which include sugarcane trash, bagasse, bagasse FA, press mud, and spent wash [61-63]. The wastes that are of economic importance are bagasse, molasses, and filter press mud [63]. Bagasse is the fibrous residue remaining after the extraction of cane juice from sugarcane. Sugarcane bagasse consists of approximately $50 \%$ of cellulose, $25 \%$ of hemicellulose, and $25 \%$ of lignin [64]. In most of the sugarcane industries, bagasse is used as a fuel, resulting in its combustion and production of ash as the end product. This waste is typically disposed of into pits and also applied on land as soil amendment in some areas [61]. BA has applications in the manufacture of low cost adsorbents and ceramic membrane filters and as additives to cement and concrete [61].

Manikandan and Moganraj [64] evaluated the consolidation and rebound properties of lime stabilized soil admixed with BA. Expansive soil from Kanchipuram district of Tamil Nadu was stabilized with 1, 2, and 3\% lime with 2, 4, and 6\% BA resulting in 9 combinations which were tested for their index properties, compaction characteristics, UCC strength, cation exchange capacity, and consolidation characteristics. The results of the investigation revealed that addition of BA to lime resulted in better stabilization performance when compared to pure lime or pure BA stabilization. The strength of the stabilized soil increased on increasing the BA content. The maximum strength was achieved at a combination of $3 \%$ 
lime plus $4 \% \mathrm{BA}$ at 14 days of curing. The compressibility characteristics also reduced greatly due to the addition of BA to lime stabilization. The coefficient of consolidation, compression index, expansion index, and recompression index reduced with addition of lime and BA. The best reduction was achieved at a combination of 3\% lime and $6 \%$ BA. They concluded that the addition of BA to lime reduces the settlement of the stabilized soil by increasing its strength and reducing its compressible nature.

Alavéz-Ramírez et al. [65] adopted sugarcane BA as an additive to stabilized compressed blocks. The investigation comprised of lime and cement stabilized blocks and one combination of lime stabilized blocks admixed with sugarcane BA. The compressed stabilized block consisted of $10 \%$ stabilizer of lime and cement. In the combination with $\mathrm{BA}$, an additional ash content of $10 \%$ was used to study its effect on lime stabilized blocks. The blocks were prepared by stabilizing sandy soil by sieving through $4.5 \mathrm{~mm}$ mesh and the components were mixed thoroughly in a rotating mixer for a period of 10 minutes making sure that the aggregates did not clump together. This was followed by an addition of calculated quantity of water and mixing for a further period of 5 minutes. The resulting mix was placed in a motorized hydraulic press and compacted by a 24ton load to dimensions of $300 \mathrm{~mm} \times 150 \mathrm{~mm} \times 120 \mathrm{~mm}$. All blocks were cured in a curing room with $90 \%$ relative humidity until testing. The cast blocks were tested for their compressive strength, both soaked and unsoaked, as well as for their flexural strength. It was seen that cement stabilized blocks produced the maximum strength of all combinations. However, it was also noticed that lime stabilized blocks with BA performed better than plain lime stabilized blocks in both soaked and unsoaked conditions. SEM and XRD analyses were performed to determine mineralogical and microstructural changes in the blocks and to detect deformities at the micro level. It was concluded that addition of $10 \%$ BA to $10 \%$ lime stabilized block significantly improved its mechanical and durability properties.

Sadeeq et al. [66] probed the effect of BA on lime stabilization of lateritic soil. Lateritic soils are soil types rich in iron and aluminum formed in wet and hot tropical areas. Mostly red in color because of iron oxides, they are formed by intensive and lasting weathering of underlying parent rocks [67]. The stabilized soil was tested for its plasticity, compaction characteristics, UCC strength, and CBR. Addition of BA to lime resulted in a reduction in its MDD and increase in OMC. Addition of BA to lime stabilized lateritic soil increased its UCC strength and CBR. $8 \%$ lime with $6 \%$ BA was found to be the optimal dosage for stabilizing the lateritic soil under investigation. The authors concluded that though the stabilized soil met the requirements for subbase course, it could not meet the requirements for adequate stabilization as recommended by Transport and Road Research Laboratory.

Muazu [68] studied the effect of up to $8 \%$ BA on the compaction characteristics of lateritic soil stabilized with up to $4 \%$ cement. It was found that addition of BA resulted in an increase in OMC and reduction in MDD of the stabilized soil. The addition of BA resulted in a decrease in cohesion and an increase in friction angle of the stabilized soil. In a related study, Muazu [69] evaluated the effect of similar combinations of BA and cement on the plasticity and particle size distribution of the stabilized soil. It was concluded that addition of BA to cement stabilized lateritic reduced liquid limit, increased plastic limit, and consequently reduced plasticity of the stabilized soil. The addition of cement and BA resulted in a reduction in fines content of the soil due to aggregation of particles as a result of stabilization. The authors recommended a dosage of 4-6\% of BA for stabilization.

Onyelowe [67] studied the effect of BA on cement stabilization of lateritic soil. The study involved cement contents of $4 \%$ and $6 \%$ whereas BA content varied from 0 to $10 \%$ by dry weight of the soil. The compaction characteristics and CBR of the stabilized soil were determined to study the performance of stabilized soil. It was evident that the two cement contents gave contrasting results with respect to MDD of the stabilized soil. MDD increased with increase in BA content for $6 \%$ cement stabilized soil whereas an opposite trend was noticed for $4 \%$ cement stabilized soil. There was a general increase in $\mathrm{OMC}$ of the stabilized soil. The increasing addition of BA to cement stabilized soil increased the CBR of the stabilized soil irrespective of the cement content.

Lima et al. [70] adopted sugarcane BA as an additive to cement in the manufacture of compressed stabilized soil blocks. Two different cement contents of $6 \%$ and $12 \%$ were adopted which were amended with three different BA contents of $2 \%, 4 \%$, and $8 \%$. The stabilized blocks were tested for their compressive strengths as well as water absorption. Additionally, masonry prisms made from BA admixed cement stabilized blocks were also prepared and tested. It was found that addition of BA to the lower cement content increased the compressive strength whereas, at higher cement content, it resulted in a slight reduction in compressive strength of the blocks. It was seen that the performance of BA admixed soil block prisms performed well in both axial and diagonal compressive strength tests. The water absorption test results produced similar but varying results for the combinations evaluated. It was concluded that BA can be incorporated in the manufacture of compressed stabilized soil blocks without affecting its mechanical performance.

2.7. Other Waste Materials. Moayed et al. [71] investigated the stabilization of saline silty sand using lime and micro silica. The primary objective of their investigation was to improve the load bearing capacity of pavements constructed on Taleghan saline soils using lime and micro silica. The soils were collected and stabilized with combinations of lime and micro silica ranging from 0 to $6 \%$. The improvement to the soil was evaluated using CBR and UCC strength tests. The lime required for soil modification was then determined from plasticity index method. At $6 \%$ addition of lime, the soil became nonplastic and, hence, up to $6 \%$ lime was adopted for stabilization. The addition of micro silica to lime stabilization resulted in an increase in the CBR value of the stabilized soil. The soaked CBR of $2 \%$ lime stabilized saline silty sand increased from $92 \%$ to close to $125 \%$ on addition of $3 \%$ micro silica. The UCC strength of lime and micro silica stabilized soil also showed similar trends in strength with the strength increasing with increasing micro silica until 3\% 
beyond which it started to reduce. Thus $2 \%$ lime with $3 \%$ micro silica was found to be the optimal dosage for improving the strength and deformation characteristics of the soil.

Kalkan [72] experimented on the stabilization of granular soils with combinations of lime and silica fume and lime and FA. Both combinations were adopted in the ratio of $1: 4$ with one part as lime and 4 parts as industrial waste material. The stabilizer mixture was added to the crushed granular soil in increments of 5\% up to a maximum of $20 \%$ of total weight. The stabilized soil samples were tested for their UCC strength and CBR. It was seen that combinations of lime and FA produced good compressive strengths and significantly high values of CBR when compared to lime-silica fume combination. However, both combinations performed better when compared to soil stabilization with industrial wastes alone.

Oza and Gundaliya [73] studied the influence of cement waste dust on the lime stabilization of black cotton soil. A comparison of cement waste dust, cement waste dust and lime, and lime stabilization of black cotton soil was performed by conducting Atterberg limits and UCC strength test. Based on the consistency limits, lime stabilization gave the least plasticity characteristics of the stabilized soil whereas cement waste dust produced the highest strength of the stabilized soil. The combination of lime and cement waste dust resulted in optimal performance with respect to both plasticity characteristics and UCC strength tests. The performance of the blend was better than the performance of lime stabilization of black cotton soil.

Ahmad et al. [74] conducted an investigation on the stabilization of peat soil using cement and palm oil fuel ash as a replacement for cement. The palm oil fuel ash was sieved through 445-micron sieve to obtain fine quality ash. Four combinations of $30 \%$ ordinary Portland cement, $20 \%$ cement with $10 \%$ palm oil fuel ash, $15 \%$ of each, and $10 \%$ cement with $20 \%$ of palm oil fuel ash combinations were adopted in stabilization. Liquid limit, specific gravity, particle size distribution, compaction characteristics, organic content, and moisture content tests were performed. The strength of the stabilized soil was determined by conducting UCC strength tests on samples of $38 \mathrm{~mm}$ diameter and $76 \mathrm{~mm}$ height, cured for three different periods of 0,7 , and 14 days. The results of the study shed light on the fact that palm oil fuel ash was capable of replacing cement in stabilization of peat soil. The combination of $20 \%$ cement with $10 \%$ of palm oil fuel ash was found to produce higher strengths when compared to even $30 \%$ cement stabilization of peat soil after 14 days of curing. However, the authors recommended a detailed study with higher curing periods of up to 180 days and other combinations of cement and additives not restricted to $30 \%$.

Seco et al. [75] investigated the treatment of expansive soils for use in construction. They adopted a variety of additives like lime, magnesium oxide, natural gypsum, rice husk FA, coal bottom ash, steel FA, and aluminate filler. The investigation concentrated on improving the swelling nature and mechanical strength of the soil. The experimental programme adopted different combinations of waste materials with soil for expansive treatment and for mechanical strength enhancement. One of the combinations used in improving mechanical strength of the stabilized soil was $4 \%$ lime with $5 \%$ rice husk FA. Out of all other combinations adopted for strength improvement, the mentioned combination produced the highest strength with curing over a period of 28 days. Unlike other research works in soil stabilization, this work did not have stabilization with pure lime to act as control for determining the effectiveness of various combinations. This was due to the fact that strengths of all combinations of treated soil were compared with that of virgin soil. Despite this fact, the combination of lime and rice husk FA producing the highest strength is a testimony of the effectiveness of the combination of the industrial waste with lime.

In a similar study, Seco et al. [76] investigated the effect of lime, magnesium oxide, rice husk FA, coal FA, and aluminate filler on Marl-rich soil. The experimental programme involved determination of OLC from CBR and UCC strength tests, following which the additives were used in combination with OLC which was fixed based on preliminary tests. A nonconventional additive called consolid system was also investigated and its performance was compared with additive based system. The additive-lime combinations were then subject to UCC strength and CBR tests. The results revealed that combination of $4 \%$ lime with $5 \%$ rice husk FA produced the best strength and bearing results at all curing periods. It was also observed that consolid system was capable of producing high strengths from 7 days of curing at low dosages of less than $1 \%$.

Chen and Lin [77] investigated the performance of soft subgrade stabilized with sewage sludge ash and cement. The soft soil was stabilized with a combination of sewage sludge ash and cement in a fixed ratio of $4: 1$ in increasing dosages of $2,4,8$, and $16 \%$ addition of the combination. The stabilized soil samples were tested for their Atterberg limits, compaction characteristics, UCC strength, CBR, triaxial compressive strength, and swelling potential. It was concluded that addition of sewage sludge ash and cement combinations to soil results in a reduction in their plasticity characteristics and improvement in their strength and CBR values resulting in the soft subgrade changing to subgrade with excellent soil. The mineralogical analysis revealed the formation of crystalline ettringite and monosulphoaluminate hydrates after the treatment with sewage sludge ash and cement.

Rahmat and Ismail [78] investigated the potential of waste paper sludge ash (WSA) as a possible material for stabilization of Lower Oxford Clay in order to conserve natural resources. They adopted WSA in combination with lime, cement, and GGBS. Quicklime stabilization of the clay with varying percentage of the stabilizer was taken as control specimen to determine the performance of blended stabilizers. The blends were added in proportions of 10,15 , and $20 \%$ by weight. The ratios of WSA-lime and WSA-cement adopted were $80: 20$ and $90: 10$. The ratios of the third combination of WSA-GGBS were $70: 30$ and $50: 50$. The tests performed included Atterberg limits, compaction characteristics, linear expansion, and UCC strength. The investigation revealed that combinations of WSA-lime performed better than that of control samples of quicklime stabilized clay in reducing the plasticity index of the soil. It was noticed that, in sulphate 
bearing clays like Lower Oxford Clay, even 365 days of curing did not result in significant gain in the strength of the soil as observed from UCC tests. However, the blends of WSA-lime and WSA-cement and WSA-GGBS produced excellent improvement in strength of the soil after 365 days of curing with the last combination producing the highest strength. The linear expansion of the blended stabilizers treated soil was lesser in comparison with plain quicklime treated samples. It was concluded that blending of WSA with lime, cement, and GGBS provided a technological, economic, and environmental advantage in stabilizing poor soils such as Lower Oxford Clay.

Lisbona et al. [79] researched the performance of calcined paper sludge (CPS) with cement in stabilization of soil with an experimental programme in the laboratory as well as a field investigation to study the in situ behavior of the stabilization process. The investigation involved stabilization of soil with cement and blend of cement and CPS in the ratios of 50:50 and $75: 25$ with the total binder content ranging between 3 and $6 \%$. The soil was blended well with the stabilizers to ensure uniform mixing and was compacted at its OMC and MDD without any mellowing period, into specimens of $152.5 \mathrm{~mm}$ diameter and $127 \mathrm{~mm}$ height, and cured for a period of 7 days before performing the UCC tests on the samples prepared. The field investigation involved stabilizing a $30 \mathrm{~cm}$ deep subgrade layer using the blends that were carefully blended at plants and taken to site in tanks and applied to the soil by dry mix methods at site. The field compaction was monitored using in situ density measurement using nuclear methods and falling weight deflectometer was used to study the performance of the stabilized subgrade. The test results indicated that the blend of cement with CPS performed better than cement or CPS individually in stabilizing the soil. It was deduced that $25: 75$ CPS to cement blend produced the highest UCC strength.

James and Pandian [80], in their study, probed the effect of waste materials press mud from sugar industry as an additive to lime and ceramic dust from demolition waste as an additive to cement in the development of early strength of the stabilized soil. The work involved the preparation of UCC strength specimens of dimensions of $38 \mathrm{~mm} \times 76 \mathrm{~mm}$ with mixtures of soil with lime and press mud and soil with cement and ceramic dust. The samples were prepared at OMC and MDD and cured for periods of 2 hours, 3 and 7 days to study the development of early strength of the stabilized soil. The study concluded that addition of press mud to lime and ceramic dust to cement resulted in quick development of strength, thereby increasing the early strength of the stabilized soil when compared to pure lime stabilized and cement stabilized soil. In a minor, modified investigation of an earlier study, James and Pandian [81] studied the effect of ceramic dust on the plasticity and swell-shrink of lime stabilized soil. Two lime contents were adopted to stabilize the soil which was admixed with four different doses of ceramic dust. It was evident that the addition of ceramic dust to lime stabilized soil resulted in the reduction in plasticity and swellshrink nature of the soil but the effect of ceramic dust was prominent at lower lime content than higher lime content.
Okonkwo et al. [82] investigated the performance of cement stabilized lateritic soil admixed with eggshell ash obtained from incineration of fowl egg shells. The soil was stabilized with $6 \%$ and $8 \%$ cement dosage with egg shell ash admixture in the range of 0 to $10 \%$ in increments of $2 \%$. All percentages of cement and egg shell ash were worked out by weight of dry soil. The stabilized soil was tested for its compaction characteristics, UCC strength, CBR, and durability characteristics. It was seen that addition of egg shell ash to cement stabilized lateritic resulted in an increase in strength of the stabilized soil by up to $35 \%$. The admixing of egg shell ash also resulted in the stabilized soil satisfying the durability characteristics with loss in strength on immersion not exceeding $20 \%$ in any of the cases.

2.8. An Evaluative Discussion. In order to make a comparative evaluation of the performance of various stabilizeradditive combinations, the results from the literature discussed in this paper have been summarized in Table 2. The table cites the optimal combination and major geotechnical properties tested and differentiates the effect of additive on stabilization performance of the primary stabilizer. Many of these investigations involved a detailed test programme that investigated several properties, but only few important parameters have been listed for ease of compilation and quick understanding on comparison. However, certain important factors need to be borne in mind while perusing the details of the compilation for comparative evaluation. The performance of the wastes as additives depends a lot on the type of soil, the type of primary stabilizer used in combination, the quantum of primary stabilizer, the quantum of additive, and the methodology of the investigation. Since variations in one or many of the said factors are inevitable, a one-onone comparison of two investigative works proves to be very difficult. This can only lead to a broad comparison of the performance of the combination of the additives and stabilizers rather than the individual stabilizer or additive. Thus, the reliability of any comparative evaluation that concludes on the effectiveness of individual additives from the results of combination stabilization can be only approximate.

A wide variety of soils have been stabilized using combinations of lime/cement and FA and in almost all of them FA has produced positive results. A majority of investigations involving combinations of FA with lime/cement have concentrated on the strength and bearing of the stabilized soil. RHA with cement/lime combination has been investigated to determine strength and bearing as well as swell potential of the stabilized soil. Both FA and RHA produce very good strengths in combination with lime/cement. Stabilization using GGBS with lime/cement has been the most common combination adopted with highly plastic, expansive clays. In such cases, GGBS produces good strength as well as swell control. PG with cement is a more common combination when compared to PG with lime. In the case of PG, the strength of the stabilized soil has been concentrated on. However, the strengths achieved by PG, in general, seem to be comparatively lower than FA and RHA. In the case of BA as well, combination with cement is more frequent compared to lime. Various other lesser known wastes have also been 


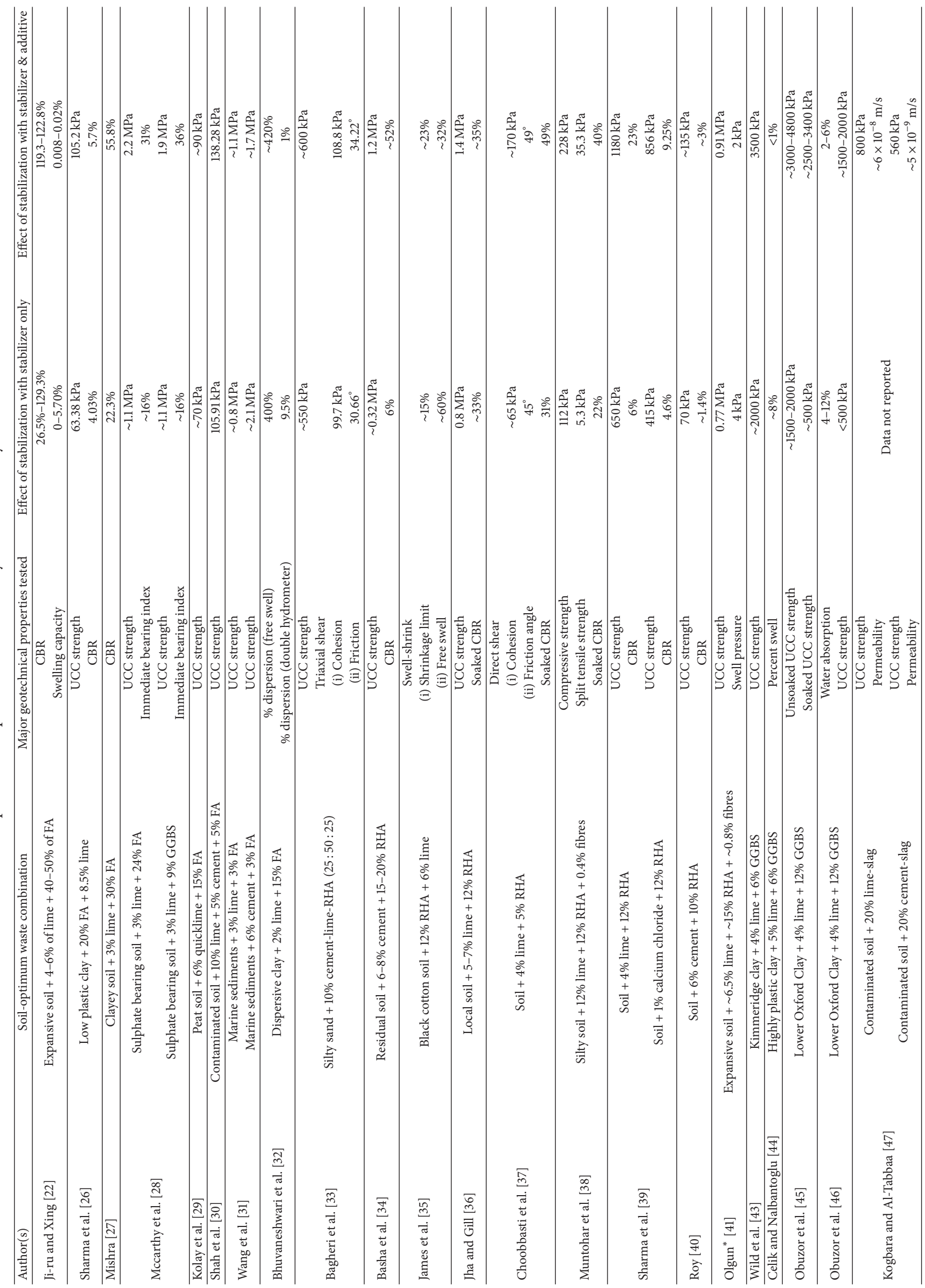



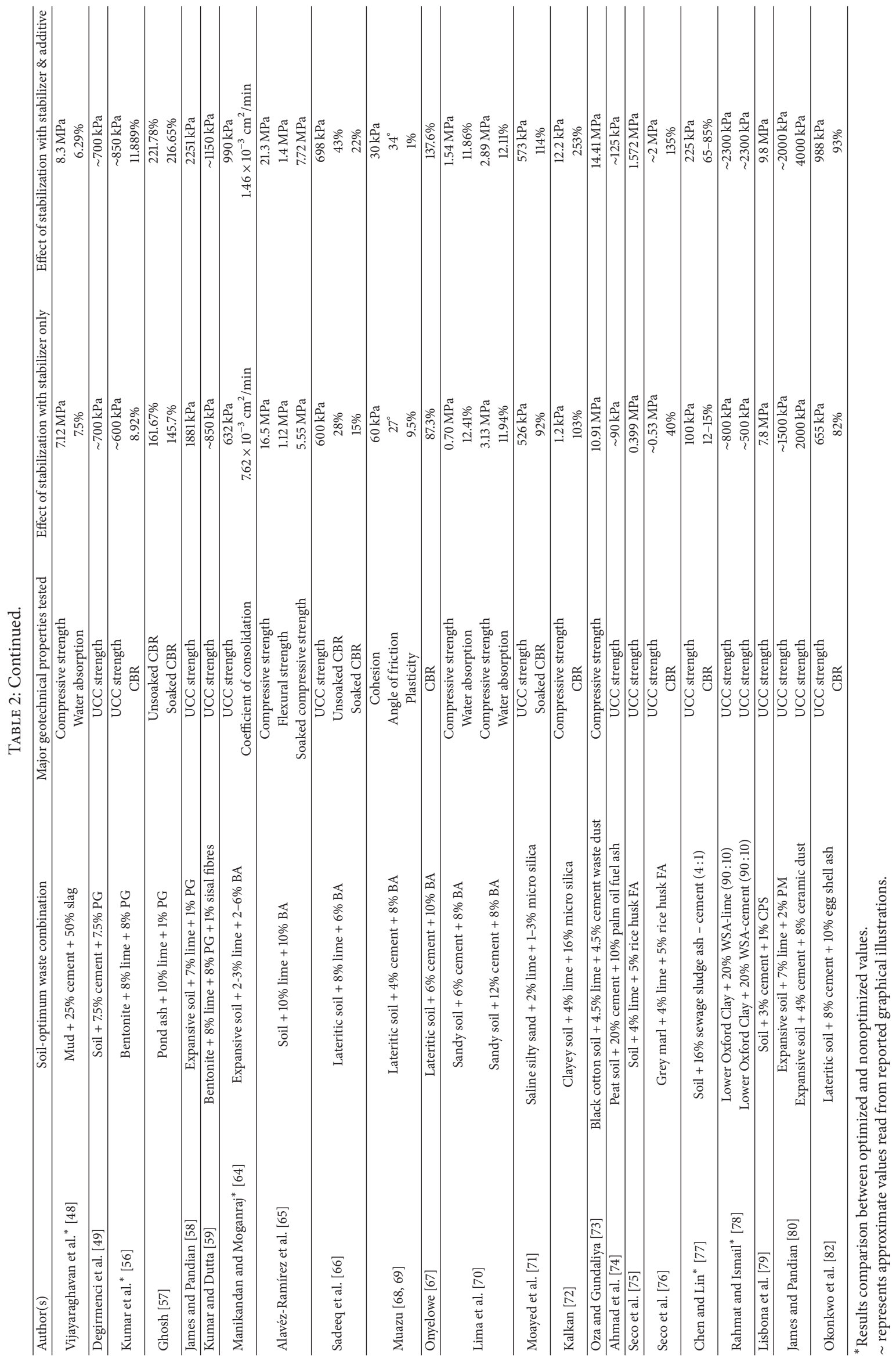
adopted in strength investigations with lime/cement out of which WSA proves to be a promising waste additive.

The overall comparison shows that FA has the advantage of being an universally and frequently adopted additive with lime/cement, supported by proven results. It is also produced in huge quantities, thereby leading to ready availability. However, there is a possibility of reduced performance when FA is combined with cement as in the case of Wang et al. [31]. RHA on the other hand has shown consistency in producing good strength results and also produces fairly good swell control effect when combined with lime/cement. GGBS has the advantage of good swell control when admixed with lime especially in sulphate-rich soils. PG produces fair strength results but is known to have small quantities of radioactive materials. Moreover, there is possibility of PG producing adverse effects with lime stabilization of soil due to presence of sulphate in PG. BA produces high strength and bearing with cement in stabilization of lateritic soils. It also produces good compressive strengths in stabilized soil blocks with cement/lime.

\section{Conclusions and Recommendations}

To summarize, generation of industrial wastes on a large scale began with industrial revolution leading to increasing standards of living but degrading environment. Alarming proportions of waste generated required a long time to be realized, leading to waste management as a discipline of concern. But it soon generated enough involvement founded upon the concern for environment, resulting in active research in the field. Soil stabilization has recently grown into an area of effective waste management. However, utilization of wastes in soil stabilization can be either as stabilizers themselves or as auxiliary additives to conventional primary stabilizers like lime/cement. This paper reviews the various works carried out using different industrial wastes like FA, RHA, PG, BA, and GGBS and a few other lesser known/adopted wastes in soil stabilization as additives to lime/cement. Based on the review of literature on utilization of solid wastes as additives to lime/cement stabilization of soils, the following conclusions can be drawn and suitable recommendations are put forward.

3.1. Conclusions. At the outset, the first inference obtained from comparison of individual results of stabilization is that addition of waste materials to lime/cement in soil stabilization produced better results than pure lime/cement stabilization with only a few exemptions which produced results on the contrary. The extent of improvement varies from meagre to enormous depending upon the combinations. Most of the researchers have concentrated on stabilization of fine-grained expansive soils/clayey soils, which may be predominantly due to the effectiveness of chemical stabilization with fine-grained soils. Works involving stabilization of silts and silty sands are minimal in literature. Effectiveness of other methods of ground improvement like grouting may be the reason for less concentration of literature in the area of stabilization of coarse grained soils. Dispersive clays have been dealt with in a number of investigations, but combinations of lime and industrial wastes in their treatment are meagre. In the available literature, combinations of cement/lime have been with pozzolans from natural sources for dispersive clay improvement.

Index properties like Atterberg limits, compaction characteristics, particle size distribution, and so forth have been predominantly dealt with by most of the researchers. Majority of the researchers have adopted UCC strength test as the preferred mode of evaluation of strength of the stabilized soil due to quickness and ease of use of the test. Other modes of strength evaluation like direct shear and triaxial shear are very limited. Permeability and compressibility seem to be least concentrated upon among the engineering properties in stabilization. Several investigators have started to adopt advanced investigations like X-ray fluorescence, XRD, EDS, SEM, transmission electron microscopy, TGA, and mercury intrusion porosimetry to analyze various properties like chemical composition, mineralogical composition, elemental composition, microstructure, thermal stability properties, pore structure composition, and so forth. However, the use of XRF, XRD, and SEM has become more common for chemical, mineralogical, and microstructural investigations of soil and stabilized soil specimens as an effective tool for explaining the chemical changes taking place and resulting microstructural modifications due to stabilization. Since a lot of stabilization research is concentrated on mitigation of volume change behavior of expansive soils, swelling investigations have been given profound importance to carry out inclusive research. They include calculation of total swell, percentage swell, swell pressure, and free swell. Nevertheless, the complimentary character of shrinkage has not been accorded the same degree of detail. A few authors, though, have evaluated the shrinkage limit and linear shrinkage of stabilized soils.

Literature indicates that lime stabilization loses effectiveness under extreme conditions like alternate cycles of wetting and drying. Thus, there have been research works to study combinations of industrial wastes with lime/cement under extreme conditions like alternate wetting and drying, freeze-thaw cycles, $\mathrm{pH}$ variations, presence of compounds such as sulphates and salts, and cyclic loading. However, investigations in these areas have been limited with a few industrial wastes as additives to lime in enhancing its resistance to loss of strength due to wetting-drying and freezethaw cycles. Investigations of cement/lime stabilization in sulphate-rich soils are also moderate. But here again, only the potential of a few industrial wastes in mitigating the disastrous effects of sulphate compounds in soil has been dealt with. Investigations pertaining to the effect of loading rate and cyclic loading on combinations of lime/cement with industrial wastes are also very finite. The potential of industrial wastes in combination with lime/cement in mitigating contaminated soil degradation, improvement of its geotechnical properties, and containment of contaminant migration has been touched upon by researchers. Available literature indicates that such wastes can play an efficient role in containment of migration of contaminants and also improve geotechnical properties of the contaminated soil. But the geoenvironmental side of soil stabilization in pollutant control still remains unexplored to its full potential. 
Curing plays an important role in the development of strength of lime as well as cement stabilized soils. However, there has been no comparative effort on the effect of different methods of curing for stabilized soils. Also, the effect of these curing conditions on combination stabilization of lime/cement and industrial wastes is limited. When using industrial wastes as additives, the reactive nature of the additive plays an important role in the progress of the chemical reaction and, hence, the stabilization achieved. The reactive nature of industrial wastes can be improved by activating them by either thermal or alkaline activation. These modes of achieving enhanced chemical reactions of additives by activation in soil stabilization with lime/cement are also very finite. A lot of lesser known industrial wastes can be effective additives to lime or cement by activation. Wastes like red mud, lead-zinc slag, phosphorus furnace slag, jarosite, kimberlite, silica fumes, sewage sludge ash, paper sludge and its ash, press mud, and egg shell ash can be researched further and activation technique can be used effectively to reveal their potential in soil stabilization with lime/cement.

3.2. Recommendations for Future Work. Lime stabilization has been and still is one of the preferred methods of soil stabilization for expansive soils. The concepts of ICL and OLC have been well established through detailed investigative works. However, in works of combinations of lime with pozzolans, very few researchers have adopted the scientifically established concepts of ICL and OLC for stabilization. A lot of researchers still adopt trial and error method for identifying lime contents for use in soil stabilization with pozzolans. It is also noticed that investigators adopted either ICL or OLC while investigating lime stabilization of soils with pozzolans. Very limited research has been carried out wherein a comparison of the effects of these two scientifically established lime contents has been dealt with. Considering the case of lime-pozzolan stabilization, work details are further limited. Thus, lime-pozzolan stabilization comparing the performance at ICL and OLC can be taken up in future investigations. Combinations of lime and waste materials as pozzolans have been dealt with in detail; however, the pozzolan contents adopted in earlier works have generally been high. Effect of low pozzolan content can be taken up for further research. Combinations of lime, cement, and industrial wastes can also be investigated in detail.

Swell control potential of FA can be probed in order to further reinforce it as a universal pozzolanic additive in soil stabilization. Permeability and compressibility performance of lime/cement stabilized soils with FA, RHA, and GGBS can be taken up to complement existing literature. BA has been very effectively used in cement concrete as replacement for binder. It has also been used in stabilized soil blocks in combination with cement as well as in soil stabilization, both individually and as an additive to cement/lime. However, earlier investigations of BA with lime have been limited with conclusions terming the combination insufficient. In order to thoroughly scrutinize the combination, more detailed investigations with different soils must be carried out. Lastly, other lesser adopted promising additives like ceramic dust, conventionally adopted as pozzolan in mortars and concrete, press mud, and WSA can be researched for revealing their full potential in lime/cement stabilization of soils.

\section{Notations Used}

$\begin{array}{ll}\text { FA: } & \text { Fly ash } \\ \text { PG: } & \text { Phosphogypsum } \\ \mathrm{Ca}(\mathrm{OH})_{2}: & \text { Calcium hydroxide } \\ \mathrm{Ca}^{2+}: & \text { Divalent calcium ion } \\ \mathrm{OH}^{-}: & \text {Hydroxyl ion } \\ \mathrm{CSH}: & \text { Calcium silicate hydrate } \\ \mathrm{CAH}: & \text { Calcium aluminate hydrate } \\ \mathrm{SiO}_{2}: & \text { Silica } \\ \mathrm{Al}_{2} \mathrm{O}_{3}: & \text { Alumina } \\ \mathrm{mm}^{2} & \text { Millimetre } \\ \mathrm{CBR}: & \text { California Bearing Ratio } \\ \mathrm{SEM}: & \text { Scanning electron microscopy } \\ \mathrm{XRD}: & \text { X-ray diffraction } \\ \mathrm{GGBS}: & \text { Ground Granulated Blast furnace Slag } \\ \mathrm{UCC}: & \text { Unconfined compression } \\ \mathrm{OMC}: & \text { Optimum moisture content } \\ \mathrm{MDD}: & \text { Maximum dry density } \\ \mathrm{RHA}: & \text { Rice husk ash } \\ \mathrm{BA}: & \text { Bagasse ash } \\ \text { WSA: } & \text { Waste paper sludge ash } \\ \mathrm{CPS}: & \text { Calcined paper sludge } \\ \mathrm{ICL}: & \text { Initial consumption of lime } \\ \mathrm{OLC}: & \text { Optimum lime content. }\end{array}$

\section{Conflict of Interests}

The authors declare that there is no conflict of interests regarding the publication of this paper.

\section{Acknowledgment}

The authors are indebted to Dr. S. Vidhya Lakshmi, Associate Professor and Head, Civil Engineering, S.A. Engineering College, Chennai, India, for spending her valuable time in proofreading this paper.

\section{References}

[1] Central Electricity Authority, Report on Fly Ash Generation at Coal/Lignite Based Thermal Power Stations and Its Utilization in the Country for the Year 2014-15, Central Electricity Authority, New Delhi, India, 2015.

[2] Central Electricity Authority, Report on Fly Ash Generation at Coal/Lignite Based Thermal Power Stations and Its Utilization in the Country for the Year 2011-12 and 2012-13, Central Electricity Authority, New Delhi, India, 2014.

[3] Central Electricity Authority, Report on Fly Ash Generation at Coal/Lignite Based Thermal Power Stations and Its Utilization in the Country for the Year 2013-14, Central Electricity Authority, New Delhi, India, 2014.

[4] Central Electricity Authority, Report on Fly Ash Generation at Coal/Lignite Based Thermal Power Stations and its Utilization in the Country for the Year 2010-11, 2011. 
[5] Central Electricity Authority, Annual Report 2010-11, Central Electricity Authority, New Delhi, India, 2011.

[6] A. K. Sabat and S. Pati, "A review of literature on stabilization of expansive soil using solid wastes," Electronic Journal of Geotechnical Engineering, vol. 19, pp. 6251-6267, 2014.

[7] P. P. Dahale, P. B. Nagarnaik, and A. R. Gajbhiye, "Utilization of solid waste for soil stabilization: a review," Electronic Journal of Geotechnical Engineering, vol. 17, pp. 2443-2461, 2012.

[8] M. Singh and A. Mittal, "Review on the soil stabilization with waste materials," International Journal of Engineering Research and Applications, no. 2, pp. 11-16, 2014.

[9] Department of Industrial Policy and Promotion, Report of the Working Group on Cement Industry for XII Five Year Plan (20122017), Department of Industrial Policy and Promotion, New Delhi, India, 2011.

[10] FICCI, "Using Steel slag in infrastructure development," FICCI Blog, 2014, http://blog.ficci.com/steel-slag/5291/.

[11] U. V. Parlikar, P. K. Saha, and S. A. Khadilkar, "Technological options for effective utilization of bauxite residue (red mud)a review generation of red mud in India," in Proceedings of the International Seminar on Bauxite Residue (Red Mud), pp. 1-18, ACC Limited, Goa, India, October 2011.

[12] Central Pollution Control Board, Assessment of Utilisation of Industrial Solid Wastes in Cement Manufacturing, New Delhi, India, 2006.

[13] Central Pollution Control Board, Guidelines for Management and Handling of Phosphogypsum Generated from Phosphoric Acid Plants (Final Draft), New Delhi, India, 2012.

[14] S. Bhuvaneswari, T. Thyagaraj, R. G. Robinson, and S. R. Gandhi, "Alternative technique to induce faster lime stabilization reaction in deeper expansive strata," in Proceedings of the Indian Geotechnical Conference (GEOtrendz '10), pp. 609-612, Mumbai, India, December 2010.

[15] Z. Metelková, J. Boháč, R. Přikryl, and I. Sedlářová, "Maturation of loess treated with variable lime admixture: pore space textural evolution and related phase changes," Applied Clay Science, vol. 61, pp. 37-43, 2012.

[16] G. Rajasekaran, "Sulphate attack and ettringite formation in the lime and cement stabilized marine clays," Ocean Engineering, vol. 32, no. 8-9, pp. 1133-1159, 2005.

[17] D. N. Little, Handbook for Stabilization of Pavement Subgrades and Base Courses with Lime, Kendall Hunt Publishing Company, Austin, Tex, USA, 1995.

[18] S. M. Rao and P. Shivananda, "Role of curing temperature in progress of lime-soil reactions," Geotechnical \& Geological Engineering, vol. 23, no. 1, pp. 79-85, 2005.

[19] J. Mallela, H. V. Quintus, and K. L. Smith, Consideration of LimeStabilized Layers in Mechanistic-Empirical Pavement Design, National Lime Association, Champaign, Ill, USA, 2004.

[20] Department of Transport and Main Roads, Lime Treatment of Clay Subgrades, Department of Transport and Main Roads, Queensland, Australia, 2000.

[21] D. N. Little, E. H. Males, J. R. Prusinski, and B. Stewart, “Cementitious stabilization," Transportation Research Board, pp. 1-7, 2000, http://pubsindex.trb.org/view.aspx?id=639997.

[22] Z. Ji-ru and C. Xing, "Stabilization of expansive soil by lime and fly ash," Journal of Wuhan University of Technology-Materials Science Edition, vol. 17, no. 4, pp. 73-77, 2002.

[23] A. K. Sabat, "Stabilization of expansive soil using waste ceramic dust," Electronic Journal of Geotechnical Engineering, vol. 17, pp. 3915-3926, 2012.
[24] S. Bhuvaneshwari, R. G. Robinson, and S. R. Gandhi, "Behaviour of lime treated cured expansive soil composites," Indian Geotechnical Journal, vol. 44, no. 3, pp. 278-293, 2014.

[25] A. Sridharan and K. Prakash, "Classification procedures for expansive soils," Geotechnical Engineering, vol. 143, no. 4, pp. 235-240, 2000.

[26] N. K. Sharma, S. K. Swain, and U. C. Sahoo, "Stabilization of a clayey soil with fly ash and lime: a micro level investigation," Geotechnical and Geological Engineering, vol. 30, no. 5, pp. 11971205, 2012.

[27] E. N. K. Mishra, "Strength characteristics of clayey sub-grade soil stabilized with fly ash and lime for road works," Indian Geotechnical Journal, vol. 42, no. 3, pp. 206-211, 2012.

[28] M. J. Mccarthy, L. J. Csetenyi, A. Sachdeva, and R. K. Dhir, "Engineering and durability properties of fly ash treated limestabilised sulphate-bearing soils," Engineering Geology, vol. 174, pp. 139-148, 2014.

[29] P. K. Kolay, M. R. Aminur, S. N. L. Taib, and M. I. S. Mohd Zain, "Stabilization of tropical peat soil from Sarawak with different stabilizing agents," Geotechnical and Geological Engineering, vol. 29, no. 6, pp. 1135-1141, 2011.

[30] S. J. Shah, A. V. Shroff, J. V. Patel, K. C. Tiwari, and D. Ramakrishnan, "Stabilization of fuel oil contaminated soil-a case study," Geotechnical and Geological Engineering, vol. 21, no. 4, pp. 415-427, 2003.

[31] D. Wang, N. E. Abriak, and R. Zentar, "Strength and deformation properties of Dunkirk marine sediments solidified with cement, lime and fly ash," Engineering Geology, vol. 166, pp. 9099, 2013.

[32] S. Bhuvaneshwari, B. Soundra, R. G. Robinson, and S. R. Gandhi, "Stabilization and microstructural modification of dispersive clayey soils," in Proceedings of the 1st International Conference on Soil and Rock Engineering, pp. 1-7, Srilankan Geotechnical Society, Colombo, Sri Lanka, August 2007.

[33] Y. Bagheri, F. Ahmad, and M. A. M. Ismail, "Strength and mechanical behavior of soil-cement-lime-rice husk ash (soilCLR) mixture," Materials and Structures, vol. 47, no. 1-2, pp. 5566, 2014.

[34] E. A. Basha, R. Hashim, H. B. Mahmud, and A. S. Muntohar, "Stabilization of residual soil with rice husk ash and cement," Construction and Building Materials, vol. 19, no. 6, pp. 448-453, 2005.

[35] J. James, S. V. Lakshmi, P. K. Pandian, and S. Aravindan, "Effect of lime on the index properties of rice husk ash stabilized soil," International Journal of Applied Engineering Research, vol. 9, no. 18, pp. 4263-4272, 2014.

[36] J. N. Jha and K. S. Gill, "Effect of rice husk ash on lime stabilization," Journal of the Institution of Engineers, vol. 87, pp. 33-39, 2006.

[37] A. J. Choobbasti, H. Ghodrat, M. J. Vahdatirad et al., "Influence of using rice husk ash in soil stabilization method with lime," Frontiers of Earth Science in China, vol. 4, no. 4, pp. 471-480, 2010.

[38] A. S. Muntohar, A. Widianti, E. Hartono, and W. Diana, "Engineering properties of silty soil stabilized with lime and rice husk ash and reinforced with waste plastic fiber," Journal of Materials in Civil Engineering, vol. 25, no. 9, pp. 1260-1270, 2013.

[39] R. S. Sharma, B. R. Phanikumar, and B. V. Rao, "Engineering behavior of a remolded expansive clay blended with lime, calcium chloride, and rice-husk ash," Journal of Materials in Civil Engineering, vol. 20, no. 8, pp. 509-515, 2008. 
[40] A. Roy, "Soil stabilization using rice husk ash and cement," International Journal of Civil Engineering Research, vol. 5, no. 1, pp. 49-54, 2014.

[41] M. Olgun, "The effects and optimization of additives for expansive clays under freeze-thaw conditions," Cold Regions Science and Technology, vol. 93, pp. 36-46, 2013.

[42] National Slag Association, "Blast Furnace Slag," 2013, http:// www.nationalslag.org/blast-furnace-slag.

[43] S. Wild, J. M. Kinuthia, G. I. Jones, and D. D. Higgins, "Effects of partial substitution of lime with ground granulated blast furnace slag (GGBS) on the strength properties of lime-stabilised sulphate-bearing clay soils," Engineering Geology, vol. 51, no. 1, pp. 37-53, 1998.

[44] E. Celik and Z. Nalbantoglu, "Effects of ground granulated blastfurnace slag (GGBS) on the swelling properties of limestabilized sulfate-bearing soils," Engineering Geology, vol. 163, pp. 20-25, 2013.

[45] G. N. Obuzor, J. M. Kinuthia, and R. B. Robinson, "Soil stabilisation with lime-activated-GGBS - a mitigation to flooding effects on road structural layers/embankments constructed on floodplains," Engineering Geology, vol. 151, pp. 112-119, 2012.

[46] G. N. Obuzor, J. M. Kinuthia, and R. B. Robinson, "Enhancing the durability of flooded low-capacity soils by utilizing limeactivated ground granulated blastfurnace slag (GGBS)," Engineering Geology, vol. 123, no. 3, pp. 179-186, 2011.

[47] R. B. Kogbara and A. Al-Tabbaa, "Mechanical and leaching behaviour of slag-cement and lime-activated slag stabilised/ solidified contaminated soil," Science of the Total Environment, vol. 409, no. 11, pp. 2325-2335, 2011.

[48] C. Vijayaraghavan, J. James, and S. Marithangam, "Cost effective bricks in construction: a performance study," International Journal of Applied Engineering Research, vol. 4, no. 3, pp. 227-334, 2009.

[49] N. Degirmenci, A. Okucu, and A. Turabi, "Application of phosphogypsum in soil stabilization," Building and Environment, vol. 42, no. 9, pp. 3393-3398, 2007.

[50] H. Tayibi, M. Choura, F. A. López, F. J. Alguacil, and A. LópezDelgado, "Environmental impact and management of phosphogypsum," Journal of Environmental Management, vol. 90, no. 8, pp. 2377-2386, 2009.

[51] L. Ã. Reijnders, "Cleaner phosphogypsum, coal combustion ashes and waste incineration ashes for application in building materials: a review," Building and Environment, vol. 42, no. 2, pp. 1036-1042, 2007.

[52] K. A. Rusch, T. Guo, and R. K. Seals, "Stabilization of phosphogypsum using class $\mathrm{C}$ fly ash and lime: assessment of the potential for marine applications," Journal of Hazardous Materials, vol. 93, no. 2, pp. 167-186, 2002.

[53] N. Degirmenci, "The using of waste phosphogypsum and natural gypsum in adobe stabilization," Construction and Building Materials, vol. 22, no. 6, pp. 1220-1224, 2008.

[54] N. Değirmenci, "Utilization of phosphogypsum as raw and calcined material in manufacturing of building products," Construction and Building Materials, vol. 22, no. 8, pp. 1857-1862, 2008.

[55] R. Shweikani, M. Kousa, and F. Mizban, "The use of phosphogypsum in Syrian cement industry: radiation dose to public," Annals of Nuclear Energy, vol. 54, pp. 197-201, 2013.

[56] S. Kumar, R. K. Dutta, and B. Mohanty, "Engineering properties of bentonite stabilized with lime and phosphogypsum," Slovak Journal of Civil Engineering, vol. 22, no. 4, pp. 35-44, 2014.
[57] A. Ghosh, "Compaction characteristics and bearing ratio of pond ash stabilized with lime and phosphogypsum," Journal of Materials in Civil Engineering, vol. 22, no. 4, pp. 343-351, 2010.

[58] J. James and P. K. Pandian, "Effect of phosphogypsum on strength of lime stabilized expansive soil," Gradevinar, vol. 66, no. 12, pp. 1109-1116, 2014.

[59] S. Kumar and R. K. Dutta, "Unconfined compressive strength of bentonite-lime-phosphogypsum mixture reinforced with sisal fibers," Jordan Journal of Civil Engineering, vol. 8, no. 3, pp. 239250, 2014.

[60] R. Naik, S. J. K. Annamalai, N. V. Nair, and N. R. Prasad, “Studies on mechanisation of planting of sugarcane bud chip settlings raised in protrays," Sugar Tech, vol. 15, no. 1, pp. 27-35, 2013.

[61] M. Balakrishnan and V. S. Batra, "Valorization of solid waste in sugar factories with possible applications in India: a review," Journal of Environmental Management, vol. 92, no. 11, pp. 28862891, 2011.

[62] N. Partha and V. Sivasubramanian, "Recovery of chemicals from pressmud-a sugar industry waste," Indian Chemical Engineer, vol. 48, no. 3, pp. 160-163, 2006.

[63] R. L. Yadav and S. Solomon, "Potential of developing sugarcane by-product based industries in India," Sugar Tech, vol. 8, no. 2-3, pp. 104-111, 2006.

[64] A. T. Manikandan and M. Moganraj, "Consolidation and rebound characteristics of expansive soil by using lime and bagasse ash," International Journal of Research in Engineering and Technology, vol. 3, no. 4, pp. 403-411, 2014.

[65] R. Alavéz-Ramírez, P. Montes-García, J. Martínez-Reyes, D. C. Altamirano-Juárez, and Y. Gochi-Ponce, "The use of sugarcane bagasse ash and lime to improve the durability and mechanical properties of compacted soil blocks," Construction and Building Materials, vol. 34, pp. 296-305, 2012.

[66] J. A. Sadeeq, J. Ochepo, A. B. Salahuddin, and S. T. Tijjani, "Effect of bagasse ash on lime stabilized lateritic soil," Jordan Journal of Civil Engineering, vol. 9, no. 2, pp. 203-213, 2015.

[67] K. C. Onyelowe, "Cement stabilized akwuete lateritic soil and the use of bagasse ash as admixture," International Journal of Science and Engineering Investigations, vol. 1, no. 2, pp. 16-20, 2012.

[68] M. A. Muazu, "Influence of compactive effort on bagasse ash with cement treated lateritic soil," Leonardo Electronic Journal of Practices and Technologies, vol. 10, no. 1, pp. 79-92, 2007.

[69] M. A. Muazu, "Evaluation of plasticity and particle size distribution characteristics of bagasse ash on cement treated lateritic soil," Leonardo Journal of Sciences, vol. 10, no. 1, pp. 137-152, 2007.

[70] S. A. Lima, H. Varum, A. Sales, and V. F. Neto, "Analysis of the mechanical properties of compressed earth block masonry using the sugarcane bagasse ash," Construction and Building Materials, vol. 35, pp. 829-837, 2012.

[71] R. Z. Moayed, E. Izadi, and S. Heidari, "Stabilization of saline silty sand using lime and micro silica," Journal of Central South University, vol. 19, no. 10, pp. 3006-3011, 2012.

[72] E. Kalkan, "Effects of waste material-lime additive mixtures on mechanical properties of granular soils," Bulletin of Engineering Geology and the Environment, vol. 71, no. 1, pp. 99-103, 2012.

[73] J. B. Oza and P. J. Gundaliya, "Study of black cotton soil characteristics with cement waste dust and lime," Procedia Engineering, vol. 51, pp. 110-118, 2013.

[74] J. Ahmad, A. S. Abdul Rahman, M. R. Mohd Ali, and K. F. Abd Rahman, "Peat soil treatment using POFA," in Proceedings of the IEEE Colloquium on Humanities, Science and Engineering 
(CHUSER '11), pp. 66-70, IEEE, Penang, Malaysia, December 2011.

[75] A. Seco, F. Ramírez, L. Miqueleiz, and B. García, "Stabilization of expansive soils for use in construction," Applied Clay Science, vol. 51, no. 3, pp. 348-352, 2011.

[76] A. Seco, F. Ramírez, L. Miqueleiz, B. García, and E. Prieto, "The use of non-conventional additives in Marls stabilization," Applied Clay Science, vol. 51, no. 4, pp. 419-423, 2011.

[77] L. Chen and D.-F. Lin, "Stabilization treatment of soft subgrade soil by sewage sludge ash and cement," Journal of Hazardous Materials, vol. 162, no. 1, pp. 321-327, 2009.

[78] M. N. Rahmat and N. Ismail, "Sustainable stabilisation of the Lower Oxford Clay by non-traditional binder," Applied Clay Science, vol. 52, no. 3, pp. 199-208, 2011.

[79] A. Lisbona, I. Vegas, J. Ainchil, and C. Ríos, "Soil stabilization with calcined paper sludge: laboratory and field tests," Journal of Materials in Civil Engineering, vol. 24, no. 6, pp. 666-673, 2012.

[80] J. James and P. K. Pandian, "A study on the early UCC strength of stabilized soil admixed with industrial waste materials," International Journal of Earth Sciences and Engineering, vol. 7, no. 3, pp. 1055-1063, 2014.

[81] J. James and P. K. Pandian, "Effect of micro ceramic dust on the plasticity and swell index of lime stabilized expansive soil," International Journal of Applied Engineering Research, vol. 10, no. 42, pp. 30647-30650, 2015.

[82] U. N. Okonkwo, I. C. Odiong, and E. E. Akpabio, "The effects of eggshell ash on the strength properties of cement stabilized lateritic," International Journal of Sustainable Construction Engineering Technology, vol. 3, no. 1, pp. 18-25, 2012. 


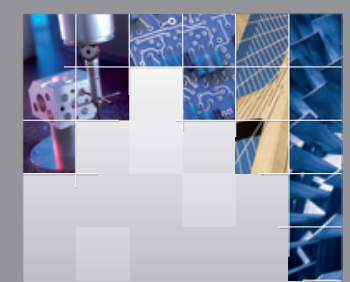

\section{Enfincering}
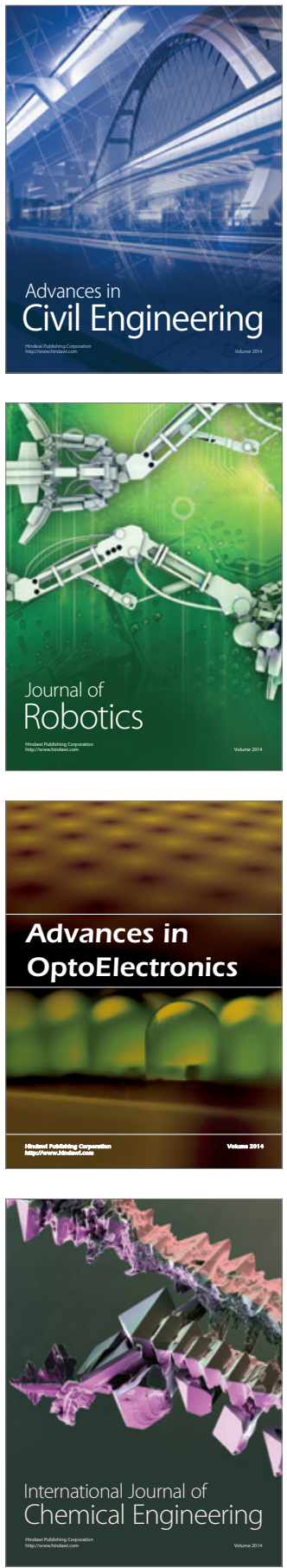

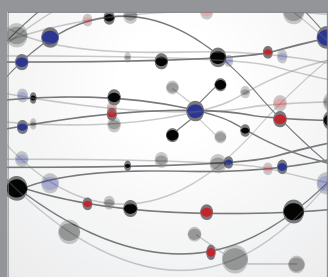

The Scientific World Journal

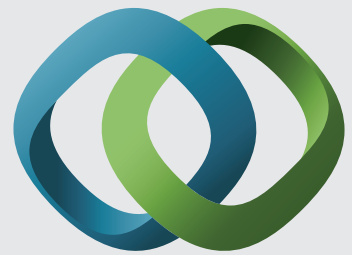

\section{Hindawi}

Submit your manuscripts at

http://www.hindawi.com
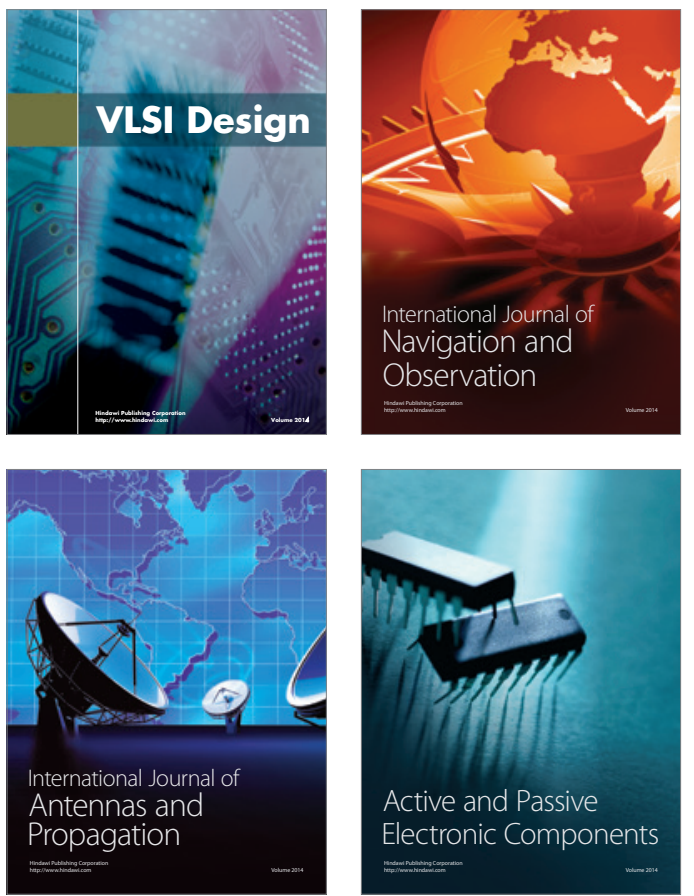
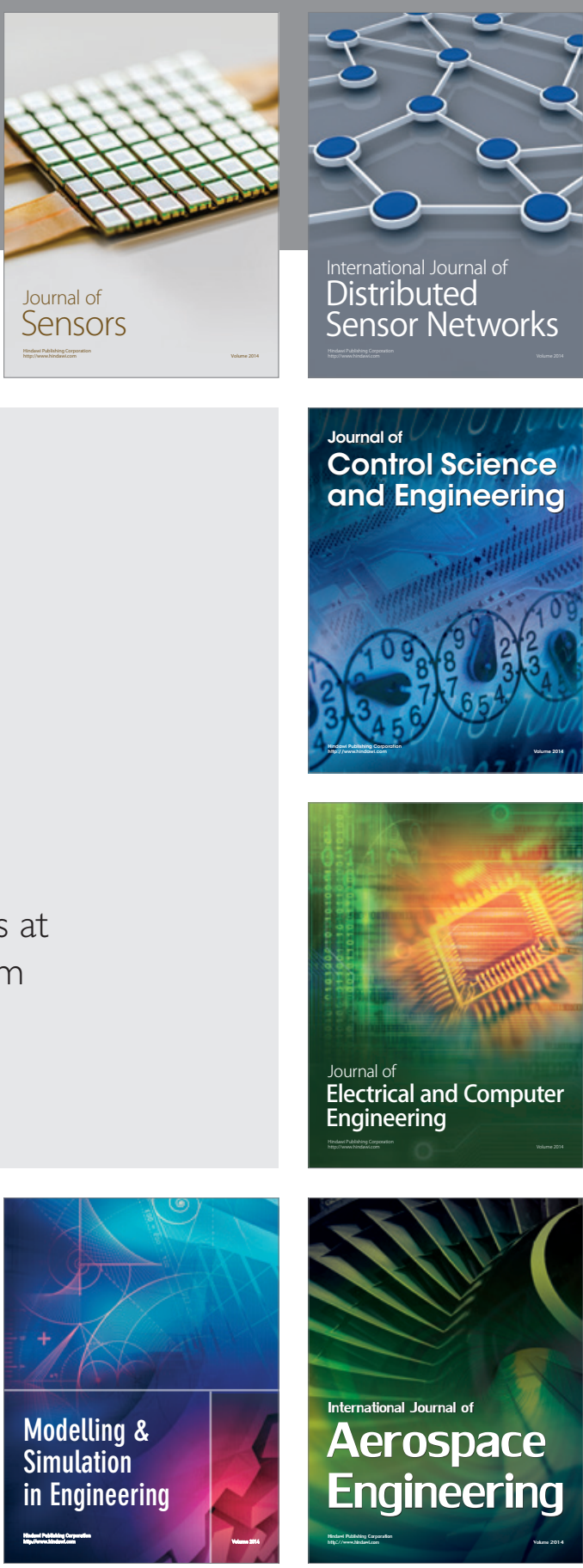

International Journal of

Distributed

Sensor Networks

Journal of

Control Science

and Engineering
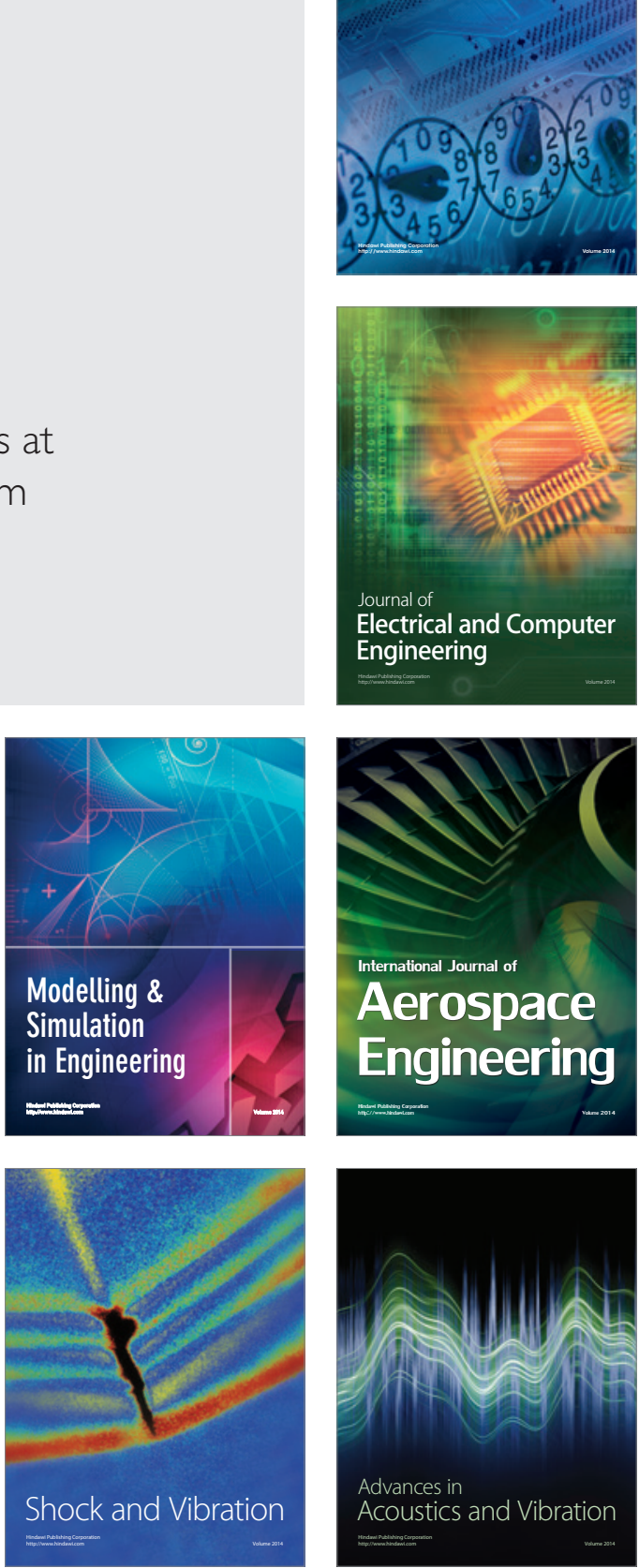